\title{
Fine structures and dynamics in auroral initial brightening at substorm onsets
}

\author{
K. Sakaguchi ${ }^{1}$, K. Shiokawa ${ }^{1}$, A. Ieda ${ }^{1}$, R. Nomura ${ }^{1}$, A. Nakajima ${ }^{1}$, M. Greffen ${ }^{2}$, E. Donovan ${ }^{2}$, I. R. Mann ${ }^{3}$, H. Kim ${ }^{4}$, \\ and M. Lessard ${ }^{4}$ \\ ${ }^{1}$ Solar-Terrestrial Environment Laboratory, Nagoya University, Japan \\ ${ }^{2}$ Department of Physics and Astronomy, University of Calgary, Alberta, Canada \\ ${ }^{3}$ Department of Physics, University of Alberta, Alberta, Canada \\ ${ }^{4}$ Space Science Center, University of New Hampshire, NH, USA
}

Received: 27 October 2008 - Revised: 14 January 2009 - Accepted: 15 January 2009 - Published: 9 February 2009

\begin{abstract}
We show four auroral initial brightening events at substorm onsets focusing on fine structures and their longitudinal dynamics, which were observed by all-sky TV cameras (30-Hz sampling) on January 2008, in Canada. For two initial brightenings started in the field of views of the cameras, we found that they started at longitudinal segments with a size of less than $\sim 30-60 \mathrm{~km}$. One brightening expanded with wavy structures and the other expanded as a straight arc. Although the two events had different structures, both brightening auroras expanded with an average speed of $\sim 20 \mathrm{~km} / \mathrm{s}$ in the first $10 \mathrm{~s}$, and $\sim 10 \mathrm{~km} / \mathrm{s}$ in the following $10 \mathrm{~s}$. The other two events show that brightening auroras developed with periodic structures, with longitudinal wavelengths of $\sim 100$ $200 \mathrm{~km}$. Assuming that the brightening auroras are mapped to the physical processes occurring in the plasma sheet, we found that the scale size $(30-60 \mathrm{~km})$ and the expanding speed $(20 \mathrm{~km} / \mathrm{s})$ of brightening auroras correspond to the order of ion gyro radii $(\sim 500-1400 \mathrm{~km})$ and Alfvén speed or fast ionflow speed $(\sim 400 \mathrm{~km} / \mathrm{s})$, respectively, in the plasma sheet.
\end{abstract}

Keywords. Magnetospheric physics (Auroral phenomena; Plasma sheet; Storms and substorms)

\section{Introduction}

The physics that causes auroral expansion during magnetospheric substorm are still unknown and are a controversial topic in space science over the decades since the auro-

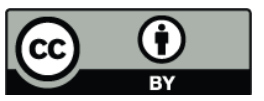

Correspondence to: K. Sakaguchi (kaori@stelab.nagoya-u.ac.jp) ral substorm was first defined by Akasofu (1964). Particularly, it is not clear whether cross-tail current disruption in the inner plasma sheet (inside $10 R_{E}$ ) is initiated first (insideout model) (e.g. Lui, 1996) or if magnetic reconnection in the near-Earth neutral line $\left(\sim 20-30 R_{E}\right)$ is initiated first (outside-in model) (e.g. Angelopoulos et al., 2008). From auroral observations, we know that the initial brightening appears at latitudes usually magnetically connected to the inner plasma sheet, and then the brightening auroras expand to higher latitudes (e.g. Lyons et al., 2002). In case of outsidein model, field-aligned currents are generated near the braking point of earthward flow (Shiokawa et al., 1998). In case of inside-out model, some plasma instabilities in the inner plasma sheet generate field-aligned currents (Lui, 2004). For both cases, since enhancements of field-aligned currents create auroral breakups on the ionosphere, dynamic variations of brightening auroras are possibly projected manifestations of physical processes in the inner plasma sheet at the beginning of a magnetospheric substorm.

Recent development of optical instruments for groundbased auroral observations, e.g. THEMIS ASIs array (Donovan et al., 2006a; Mende et al., 2008), reveals new auroral features at substorm expansion-phase onset that we could not detect previously due to limitation of spatial and temporal coverage and/or resolution. Donovan et al. (2006b) reported a pseudo breakup occurred on a pre-existing auroral arc with a brightening that consisted of eastward propagating beads with a wavelength of $\sim 100 \mathrm{~km}$ and an azimuthal propagation speed of $\sim 5 \mathrm{~km} / \mathrm{s}$. Liang et al. (2008) found intensification of aurora occurring within $\sim 10 \mathrm{~s}$ over an arc segment of $\sim 01: 00$ MLT and featuring wave-like formations with longitudinal wavelengths between 50 and $200 \mathrm{~km}$. Similar

Published by Copernicus Publications on behalf of the European Geosciences Union. 


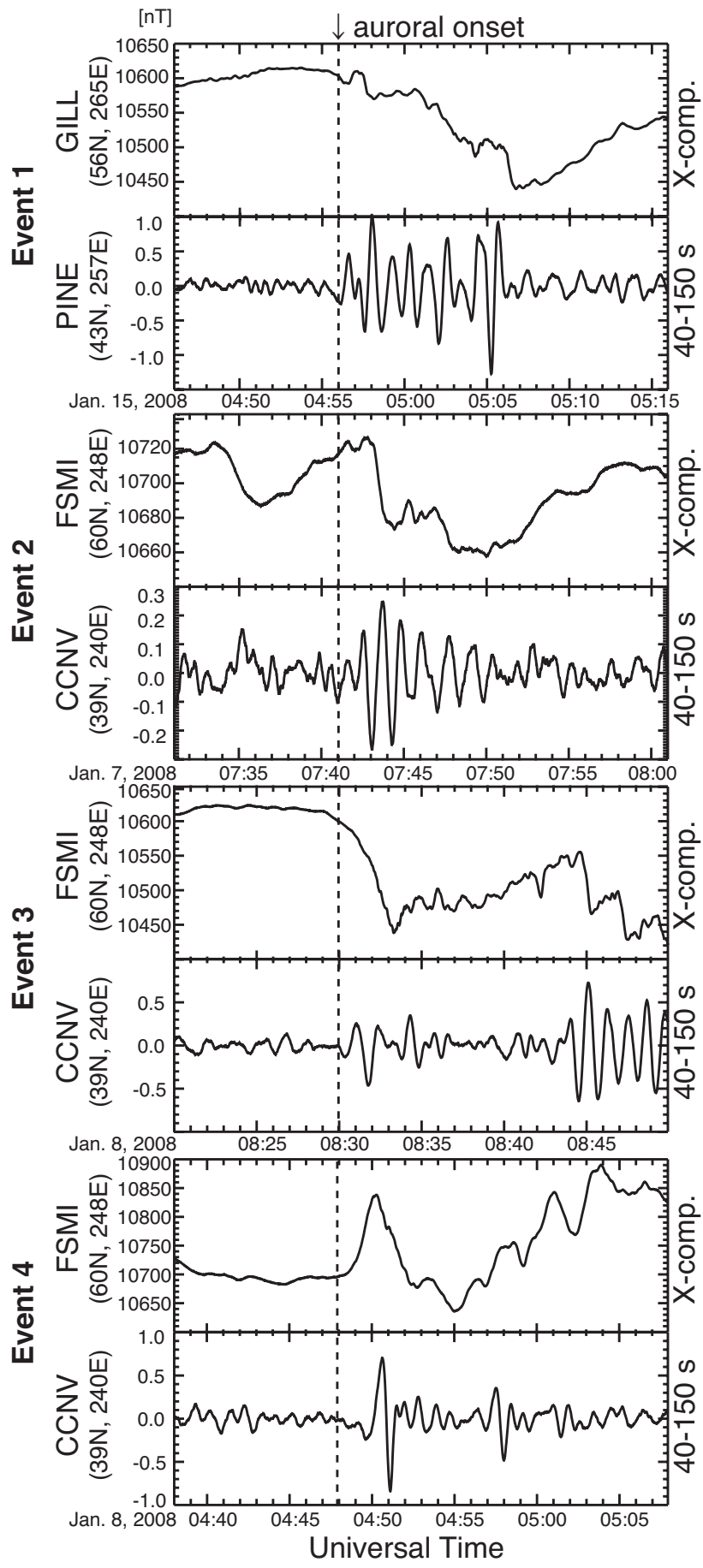

Fig. 1. X-component magnetic field variations observed at auroral onset sites and $\mathrm{X}$-component filtered magnetic field fluctuations in the Pi2 range (periods $\sim 40-150 \mathrm{~s}$ ) observed at mid-latitude sites during the 4 events of auroral initial brightenings reported in this paper. Vertical dashed line indicates the onset time of auroral brightenings. structures were seen by Rae et al. (2009) at scales along the arc of $\sim 70 \mathrm{~km}$ (see also Freidrich et al., 2001). Significant information will be revealed by auroral dynamics at the initial stages of auroral expansions in order to solve the questions of the substorm onset mechanism. In this paper, we show fine structures and dynamics of auroras at the initial brightenings using $30-\mathrm{Hz}$ resolution optical images.

\section{Observation}

High time-resolution auroral images that were used in this report were obtained during the 2-week THEMIS-ground campaign observations in a new moon period of January 2008 at Fort Smith (geographic latitude $60.0^{\circ} \mathrm{N}$, longitude $248.1^{\circ} \mathrm{E}$, dipole geomagnetic latitude $\left.67.0^{\circ}\right)$ and Gillam $\left(56.4^{\circ} \mathrm{N}\right.$, $265.4^{\circ} \mathrm{E}, 65.6^{\circ}$ ), Canada (Shiokawa et al., 2009). These two stations are located under the auroral oval. The observations were carried out using image-intensified panchromatic allsky TV cameras with a sampling rate of $30 \mathrm{~Hz}$.

During the campaign, two auroral initial brightenings were observed at substorm onsets near the center of the field of view (FoV) of the cameras with no-cloud condition. Temporal variations of these brightening auroras are shown in Sect. 3, and their longitudinal motions are shown in Sect. 4. Characteristic auroral dynamics just after initial brightenings are shown in Sect. 5 using the other two events, for which initial brightenings started beyond the FoV of the cameras.

Figure 1 shows X-component magnetic field variations observed at auroral onset sites at Fort Smith and Gillam from the magnetometers in the CARISMA array (Mann et al., 2008; www.carisma.ca) and X-component magnetic field fluctuations filtered for the periods of $\mathrm{Pi} 2$ magnetic pulsation ( $T=40-150)$ observed at mid-latitude sites in the onset-site longitude. The vertical dashed lines show the onset times of the auroral brightenings. All four events are accompanied by mid-latitude $\mathrm{Pi} 2$ geomagnetic pulsations, which are well known as an indicator of substorm onset. These events, except for event 4 , were also accompanied by decrease (in events 1-3) and increase (in event 4) in X-component magnetic fields at the sites where the brightenings were observed, indicating enhancement of westward and eastward electrojet currents, respectively.

\section{Fine structures in initial brightening}

\subsection{Event 1: Ray structure}

On 15 January 2008, an auroral substorm occurred at Gillam in the pre-midnight magnetic local time at 22:23 MLT ( 04:56 UT). The initial brightening started at slightly northward from the center of the FoV of the all-sky camera. The magnetic field data in Fig. 1 shows decrease in X-component magnetic fields at 04:56 UT with an onset of $\mathrm{Pi} 2$ pulsation at mid-latitude. This event, however, would be categorized as a 
pseudo breakup, since brightening auroras did not develop on global scale and the geomagnetic $\mathrm{X}$ components decreased only $\sim 150 \mathrm{nT}$. Partial all-sky images with a separation of $1 \mathrm{~s}$ are shown in false color in Fig. 2. The images are converted to the geographical coordinates by assuming an auroral altitude of $100 \mathrm{~km}$. Top is north and right is west. Vertical and horizontal sizes of the image are $80 \mathrm{~km}$ and $300 \mathrm{~km}$, respectively. Left column (a) shows 0.1-s averaged images calculated using three successive images. Right column (b) shows differential images in color obtained by calculating differences of the images shown in Fig. 2a every $1 \mathrm{~s}$. Magnetic zenith is located just below the bottom edge of the images near the center in longitudes. From Fig. $2 \mathrm{a}$ we found that the auroral brightening appeared along the poleward boundary of a diffuse auroral arc and developed westward with showing a ripple-like motion. The wavelengths of the ripples are in an order of $100 \mathrm{~km}$. Details of the brightening features are seen in Fig. 2b. As shown in the second panel of Fig. 2b, the initial brightening appeared at 04:55:38 UT over a $\sim 30$ $\mathrm{km}$ width in longitude in $1 \mathrm{~s}$. From Fig. $2 \mathrm{~b}$, we also found that fine ray structures existed in the brightening aurora, of which wavelengths are in an order of $\sim 10 \mathrm{~km}$ and are likely subdivided with time.

\subsection{Event 2: Arc structure}

The other auroral substorm event occurred at 23:28 MLT (07:41 UT) on 7 January 2008 in the FoV of the all-sky camera at Fort Smith. The magnetic field data in Fig. 1 shows that it took place with the mid-latitude $\mathrm{Pi} 2$ pulsation after a small activity (pseudo-onset) from 07:34 UT. This event would be also categorized as a pseudo breakup, since the geomagnetic X components decreased only $\sim 60 \mathrm{nT}$. The time series of partial all-sky images every $2 \mathrm{~s}$ focusing on the initial brightening region are shown in Fig. 3, in the same format as that in Fig. 2. Vertical and horizontal sizes of the images are $120 \mathrm{~km}$ and $380 \mathrm{~km}$, respectively. As shown in Fig. 3a, the auroral initial brightening started between two pre-existing arcs that can be recognized near the top and bottom edges of the images. The brightening region straightly expanded eastward as an arc. The latitudinal width of brightening arc is $\sim 10 \mathrm{~km}$. Time sequence of differential images clearly shows that the brightening arc simply intensified and developed to the longitudinal direction without any depletion (blue color) at the first $20 \mathrm{~s}$. As shown in Fig. 3b, the brightening initially appeared at 07:41:14 UT as a longitudinal segment over $\sim 60 \mathrm{~km}$ in $2 \mathrm{~s}$.

\section{Expansion speed}

Longitudinal expansion speeds of brightening auroras are described in this section. Figure 4 shows differential auroral intensities over $1 \mathrm{~min}$ in east-west segments at geographic latitudes (a) $56.8^{\circ} \mathrm{N} \pm 0.2^{\circ}$ and (b) $59.6^{\circ} \mathrm{N} \pm 0.1^{\circ}$ which are
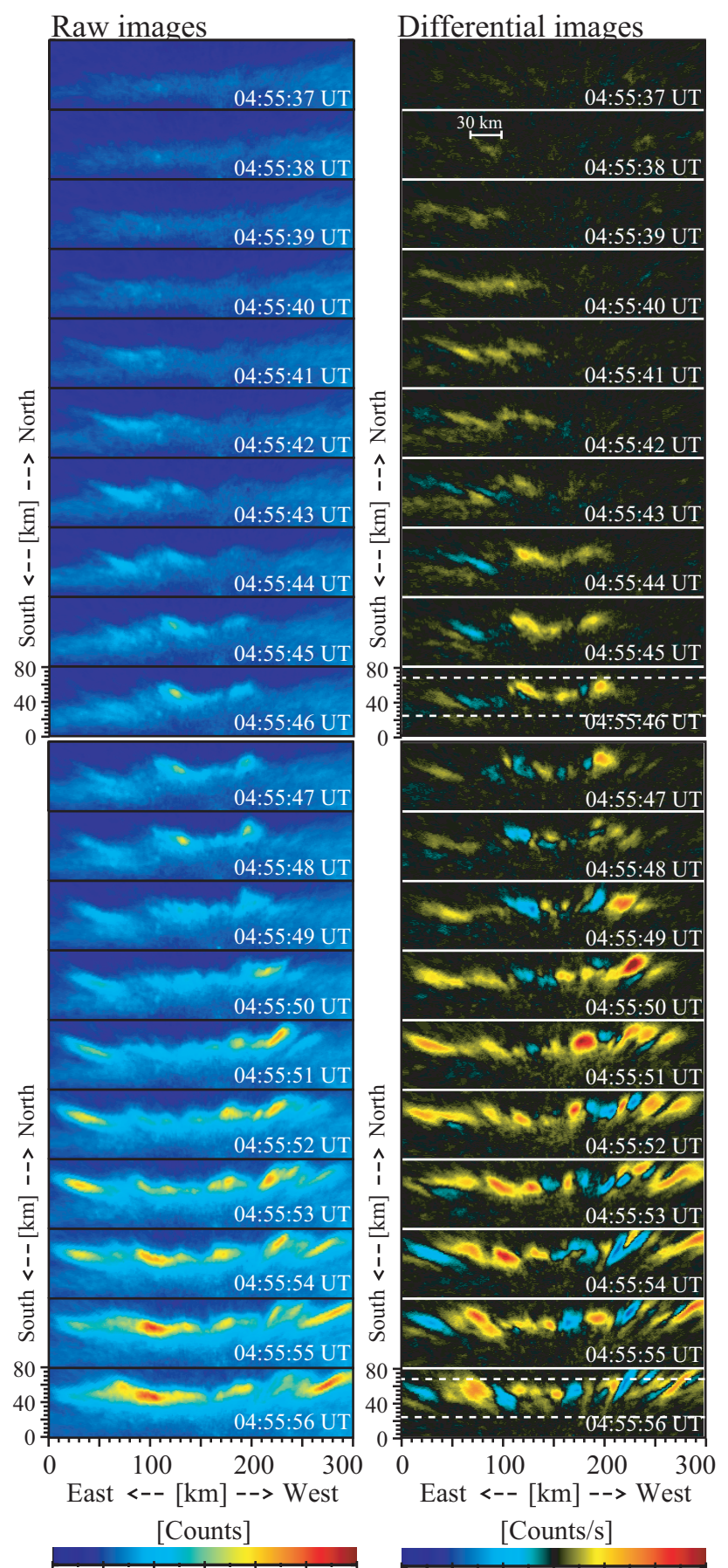

$\begin{array}{llllllllllllllll}20 & 42 & 63 & 85 & 107 & 128 & 150 & -40 & -27 & -13\end{array}$

( a )

(b)

Fig. 2. Temporal sequence of ray-like brightening auroral images every 1 s observed at substorm onset at Gillam on 15 January 2008. (a) Left column consists of averaged images over $0.1 \mathrm{~s}$ in false color. (b) Right column consists of differential images, showing increase (yellow-red) and decrease (blue) of auroral intensity during $1 \mathrm{~s}$. A vertical width between two white dashed lines at bottom and middle panels in column (b) indicate the integration range to get Fig. 4a. The magnetic zenith is located beyond bottom of images. 


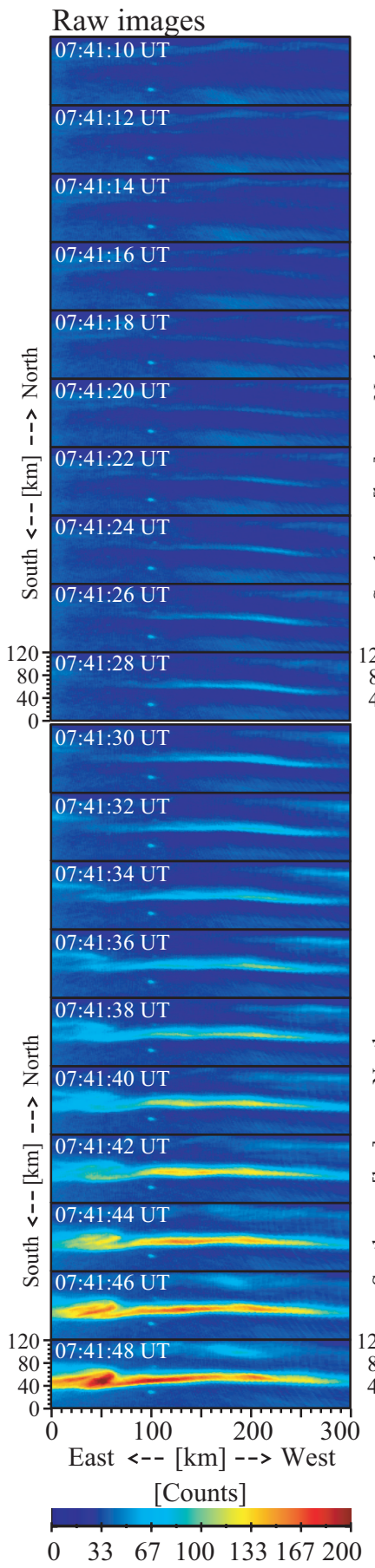

( a )

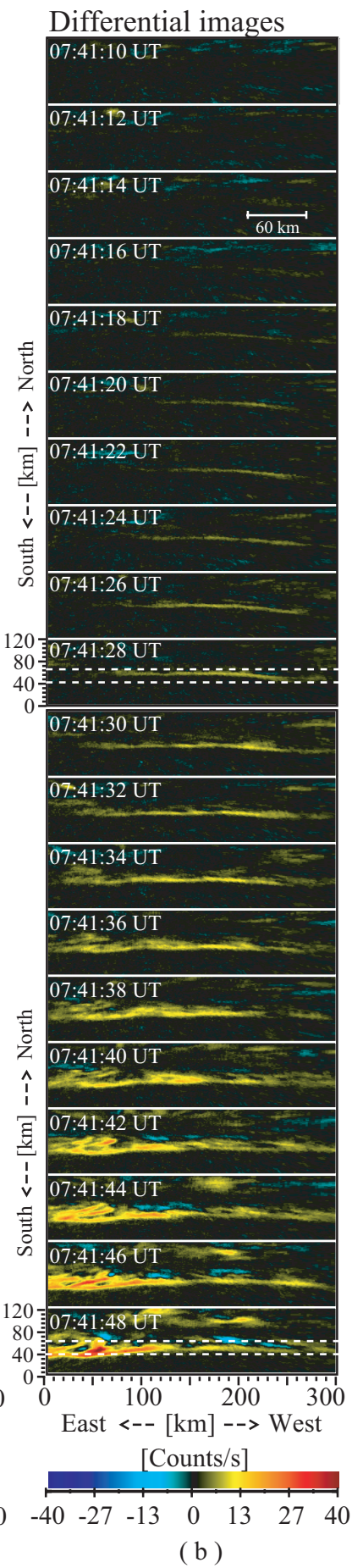

( b )
Fig. 3. Temporal sequence of ark-like brightening auroral images every $2 \mathrm{~s}$ observed at substorm onset at Fort Smith on 7 January 2008. (a) Left column consists of averaged images over $0.1 \mathrm{~s}$ in false color. (b) Right column consists of differential images, showing increase (yellow-red) and decrease (blue) of auroral intensity during $1 \mathrm{~s}$. A vertical width between two white dashed lines at bottom and middle panels in column (b) indicate the integration range to get Fig. 4b. The magnetic zenith is located at top of images. the latitudes where the brightenings started for the events shown in Figs. 1 and 2, respectively. Integration ranges which we took to get Fig. 4 are shown by two dashed lines in Figs. $2 b$ and $3 b$. The horizontal axis is longitudinal distance [degree] (1 degree $~ 60 \mathrm{~km}$ ), where left and right correspond to west and east, respectively. Colors show difference $\mathrm{dI} / \mathrm{dt}$ [counts/s] of 1-s averaged auroral intensity. The white contour correspond to $\mathrm{dI} / \mathrm{dt}=$ (a) 10 and (b) 6 . From these white lines, the longitudinal speeds of expansion were determined.

In case of event 1 , the initial brightening appeared over a longitudinal distance of $30 \mathrm{~km}$ in $1 \mathrm{~s}$ at 04:55:38 UT, as shown in Fig. 2. From Fig. 4a, we found that the frontline of wavy structures developed with an average speed of $\sim 20 \mathrm{~km} / \mathrm{s}$ westward in the first $10 \mathrm{~s}$ at 04:55:38-04:55:48 UT. In the next $10 \mathrm{~s}$ at 04:55:48-04:55:56 UT, the westward speed decreased to $\sim 12 \mathrm{~km} / \mathrm{s}$. The eastward speed was only $\sim 6 \mathrm{~km} / \mathrm{s}$ at 04:55:44-04:55:52 UT. Small structures are seen moving both directions in the brightening aurora. In case of event 2 , the brightening started as an arc over a $\sim 60-\mathrm{km}$ segment at 07:41:14 UT in $2 \mathrm{~s}$, as shown in Fig. 3. From Fig. 4b, we found that the arc expanded with an average speed of $\sim 23 \mathrm{~km} / \mathrm{s}$ eastward in the first $10 \mathrm{~s}$ at 07:41:20-07:41:30 UT. In the next $10 \mathrm{~s}$ at 07:41:30-07:41:40 UT, the eastward speed decreased to $\sim 11 \mathrm{~km} / \mathrm{s}$. The speed to the westward direction was $\sim 12 \mathrm{~km} / \mathrm{s}$ at 07:41:22-07:41:28 UT. Focusing on the first stage of the initial brightenings, we found that both brightenings possibly started from a very small point in a view of 1-s temporal resolution.

\section{Repeating structures in the edge of brightening aurora}

\subsection{Event 3}

The auroral substorm, which was observed in the postmidnight magnetic local time at 00:24 MLT (08:30 UT) on 8 January 2008, started at the western edge of the all-sky images at Fort Smith. The magnetic field data in Fig. 1 shows sudden decrease in X-component magnetic fields at 08:29 UT with a Pi2 pulsation at mid-latitude. Although the initial brightening seemed to start beyond the FoV, our $30-\mathrm{Hz}$ camera observed characteristic longitudinal expansion of the aurora. Figure 5 shows 0.1 -s averaged auroral images from 08:30:02 UT to 08:31:35 UT every $3 \mathrm{~s}$. Vertical and horizontal sizes of the images are $100 \mathrm{~km}$ and $400 \mathrm{~km}$, respectively. Bright twisted auroras appeared from the west and propagated eastward with a velocity of $\sim 4 \mathrm{~km} / \mathrm{s}$. The scale size and the intensities of the twisted vortices became larger in time. Separations between the vortices were $\sim 50-100 \mathrm{~km}$ in longitude. Similar vortex features were observed by Friedrich et al. (2001). 


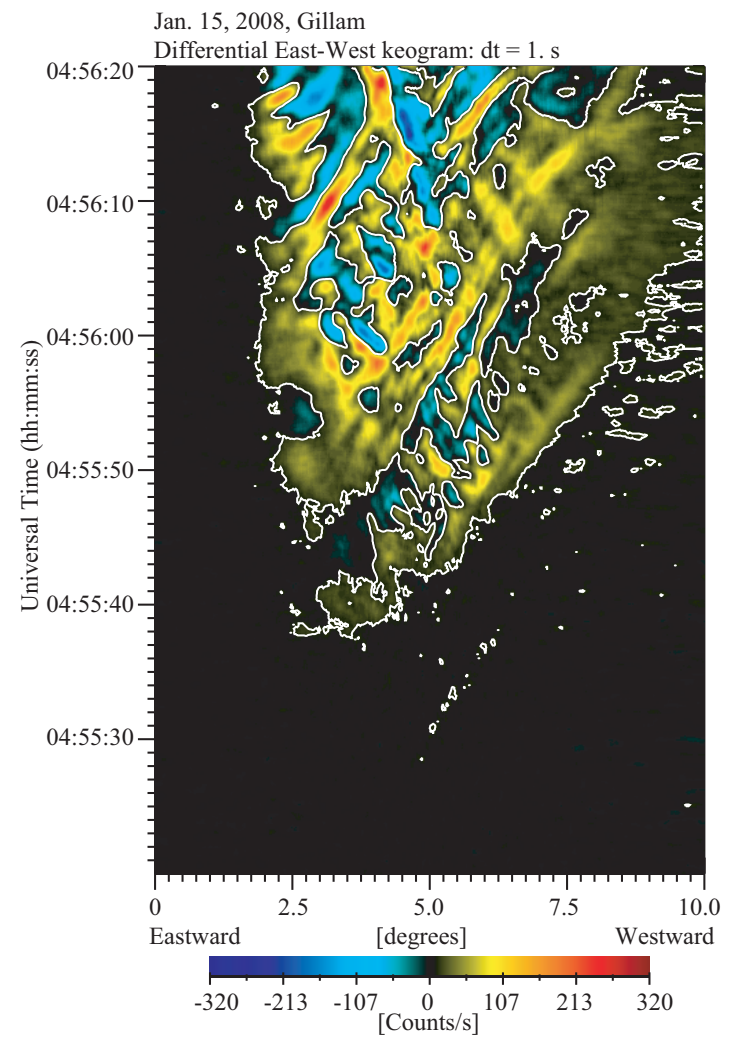

( a )

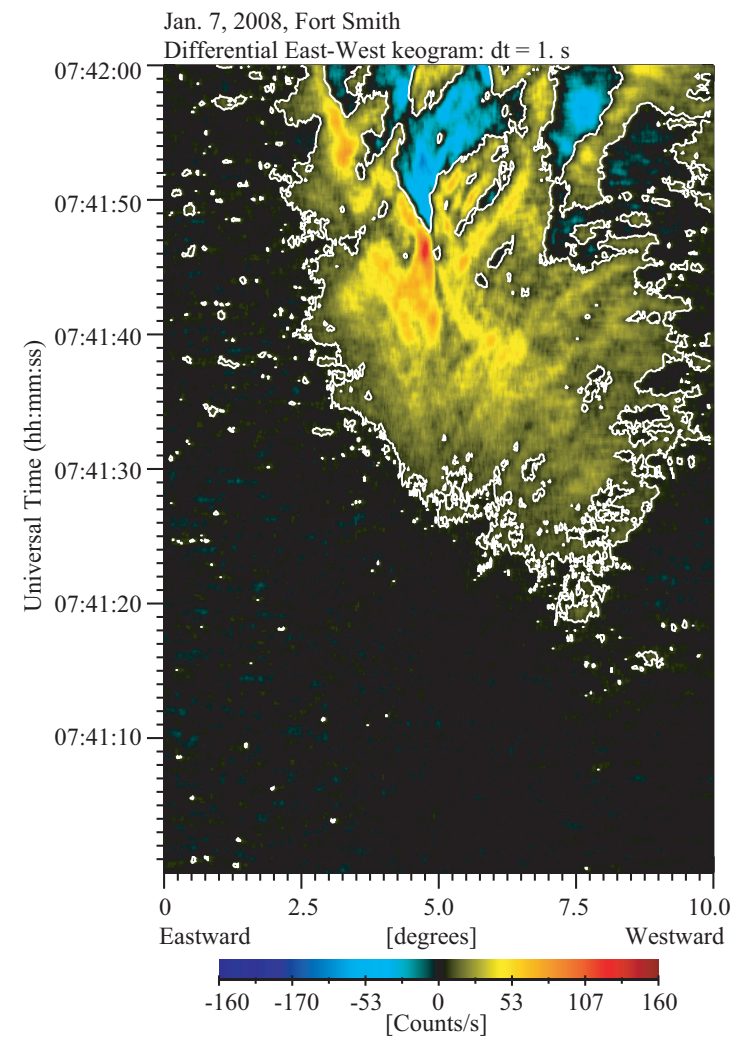

( b )

Fig. 4. East-west cross section of time-differential auroral intensity $\mathrm{dI} / \mathrm{dt}$ [counts/s] at geographic latitudes of (a) $56.8^{\circ} \mathrm{N} \pm 0.2^{\circ}$ for event 1 and (b) $59.6^{\circ} \mathrm{N} \pm 0.1^{\circ}$ for event 2 . These latitudes are those where the brightenings started. Differential counts are integrated between two dashed lines shown in Figs. $2 \mathrm{~b}$ and $3 \mathrm{~b}$. The vertical axis is time increasing upward. The horizontal axis is distance [degrees] along the above geographic latitudes. The white contour correspond to $\mathrm{dI} / \mathrm{dt}=$ (a) 10 and (b) 6 .

\subsection{Event 4}

For the event 4 , an auroral substorm was observed in the premidnight magnetic local time at 20:42 MLT (04:48 UT) on 8 January 2008 at Fort Smith. The magnetic field data in Fig. 1 shows sudden increase in $\mathrm{X}$-component magnetic fields at 04:49 UT with a Pi2 pulsation at mid-latitude. Figure $6 \mathrm{a}$ and b shows east-west keogram at 04:47-04:50 UT and 0.1-s averaged images at 04:48:00-04:48:55 UT, respectively. Bright auroras appeared near the northeastern edge of the all-sky images from the out of FoV of the camera and propagated westward repeatedly with a period of $\sim 15 \mathrm{~s}$. The auroral intensity gradually increased with increasing time. Westward speeds of the auroras were $\sim 8 \mathrm{~km} / \mathrm{s}$ for the auroral bead appeared at $\sim 04: 47 \mathrm{UT}$, gradually increased by turn, and finally reached $\sim 16 \mathrm{~km} / \mathrm{s}$ for a bead appeared at $\sim 04: 49$ UT. Average separation between these auroral structures was $\sim 100$ $200 \mathrm{~km}$. After 04:49 UT, the westward speeds started to decrease.

The black and gray lines on Fig. 6a show fluctuations of X- and Y- component magnetic field (40-s running averages are subtracted in order to focus on the $\sim 15$-s period waves seen in the auroral images), respectively, observed by a search coil magnetometer at Fort Smith, which sampled data at $10 \mathrm{~Hz}$. We found that both components of magnetic fields fluctuated with a period $\sim 15 \mathrm{~s}$ in correlation with the westward propagation of auroral bead structures, suggesting that field-aligned and ionospheric currents are accompanied by the westward auroral motion.

\section{Discussion}

Fine structures in the brightening auroras of events 1 and 2 were quite different, i.e. event 1 developed as ray structures and event 2 expanded as a straight arc. However, we found that the longitudinal speeds of expansion were similar for both events. The brightening aurora appeared simultaneously as longitudinal segments over $30-60 \mathrm{~km}$ in $1 \mathrm{~s}$. Then, one side of the segment expanded longitudinally with an average speed of $\sim 20 \mathrm{~km} / \mathrm{s}$ at the first $10 \mathrm{~s}$. At the next $10 \mathrm{~s}$, the speed decreased to $\sim 10 \mathrm{~km} / \mathrm{s}$. The other side of the segments had speeds less than or almost half of the faster side. We should note that, however, if auroral signatures is subject to 

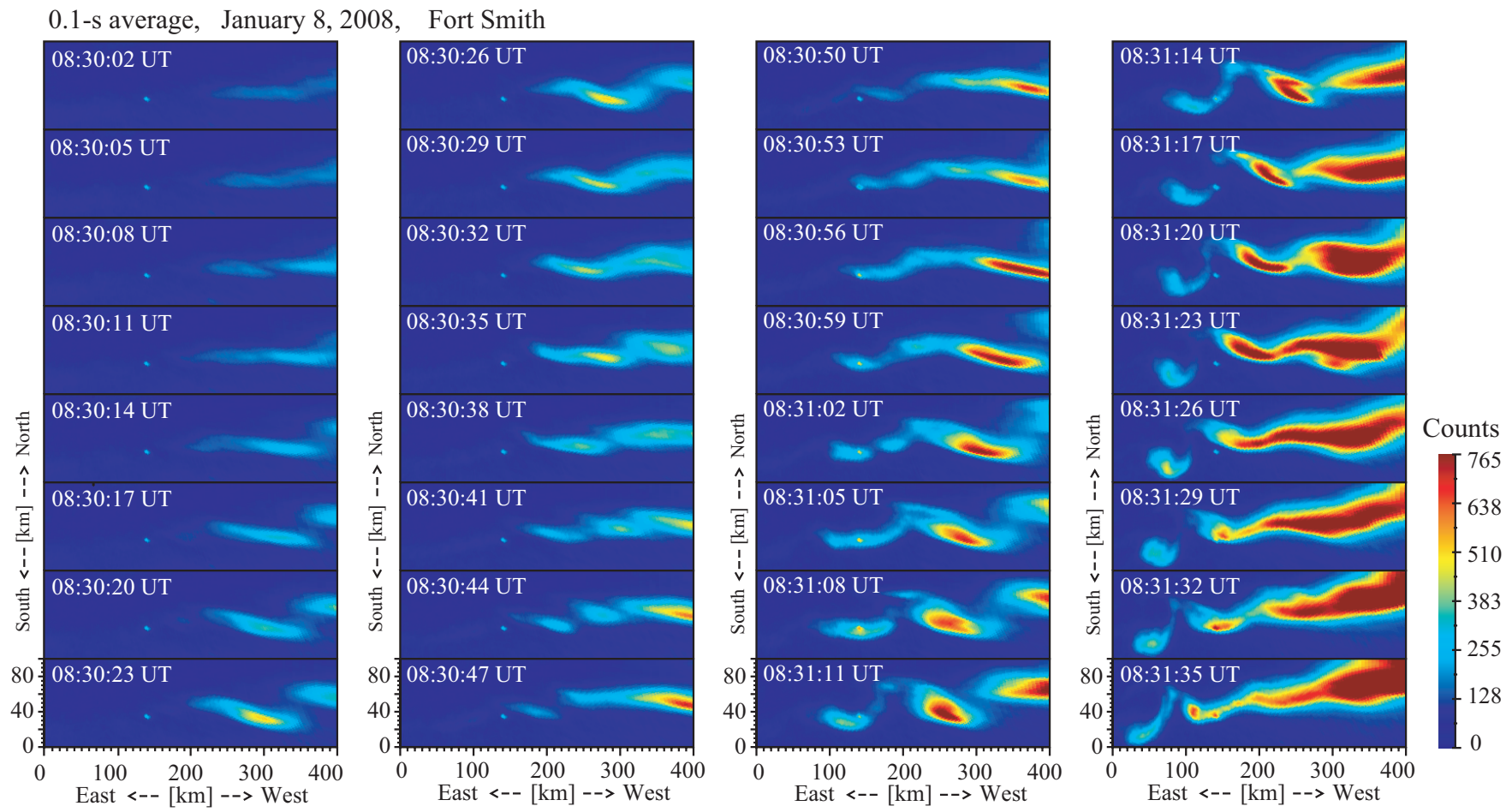

Fig. 5. Brightening auroral images every 3 s observed at 08:30:02-08:31:35 UT at Fort Smith on 8 January 2008. These images are averages over $0.1 \mathrm{~s}$.

the threshold effect that auroras are invisible when the brightness falls below a threshold, it is not possible to separate the threshold effect from true propagations in the first growth time scale.

In order to consider possible mechanisms triggering the auroral brightenings, the longitudinal size and expansion speeds of initial brightenings were projected to the magnetosphere using Tsyganenko 89 magnetic field model (T89) (Tsyganenko et al., 1989). At a traced point of $\sim 10 R_{E}$ on the magnetospheric equatorial plane, the sizes of the brightening segments of $30-60 \mathrm{~km}$ in the ionosphere are roughly translated to $600-1200 \mathrm{~km}$ in the magnetosphere, and the initial speed of $20-\mathrm{km} / \mathrm{s}$ in longitudinal directions at the ionosphere is translated to $400 \mathrm{~km} / \mathrm{s}$ in the azimuth directions in the magnetosphere.

From the magnetic field intensity $(\sim 12 \mathrm{nT})$ obtained by T89 at the source magnetosphere, ion gyro radii is $\sim 500$ $1400 \mathrm{~km}$ for $1-10 \mathrm{keV}$ protons. Thus, the substorm triggering process can be started from a scale size of or less than ion gyro radii in the plasma sheet. This result indicates that in case of auroral substorms caused by current disruptions due to plasma instabilities in the plasma sheet the characteristic length of the plasma instability is less than ion gyro radius and that the triggering physics is not MHD scale phenomena.

Longitudinal expanding speeds of brightenings are translated to $400 \mathrm{~km} / \mathrm{s}$ in the plasma sheet. It is comparable to the
Alfvén speed in the plasma sheet. The fast-ion bulk flows associated with substorms in the plasma sheet also has a speed of $\sim 400 \mathrm{~km} / \mathrm{s}$ (Baumjohann et al., 1989; Angelopoulos et al., 1994). Thus, the longitudinal expansion speeds of brightening aurora may results from generation of upward fieldaligned currents by the shear of fast ion flow or by some type of Alfvén waves.

Structures with wavelength of $\sim 100 \mathrm{~km}$ in longitudinal directions are recognized in wavy brightening auroras for event 1 and repeated structures in events 3 and 4 . Structures of this scale size have been reported by Donovan et al. (2006b), Liang et al. (2008), and Rae et al. (2009) and may be related to the scale size of magnetospheric instabilities that are responsible for the substorm onset (e.g. Cheng, 2006). As discussed by Shiokawa et al. (2009) the 10-km scale ray structures observed during event 1 . We consider such small ray structures were formed by resonant accelerations of electrons with inertia Alfvén waves at altitudes of thousands of $\mathrm{km}$ above auroras since electron inertia length is $\sim 1-10 \mathrm{~km}$ at the altitudes (e.g. Stasiewicz et al., 2000). In other words, such small-scale structure can be modulated in the acceleration region and cannot be projected to the ionosphere directly from the magnetosphere. For event 4, we found repeating westward motion of auroral arcs, which were associated with both $\mathrm{X}$ - and $\mathrm{Y}$ - components magnetic field fluctuations with a period of $\sim 15 \mathrm{~s}$. This fact indicates that the source region in the magnetosphere has some 


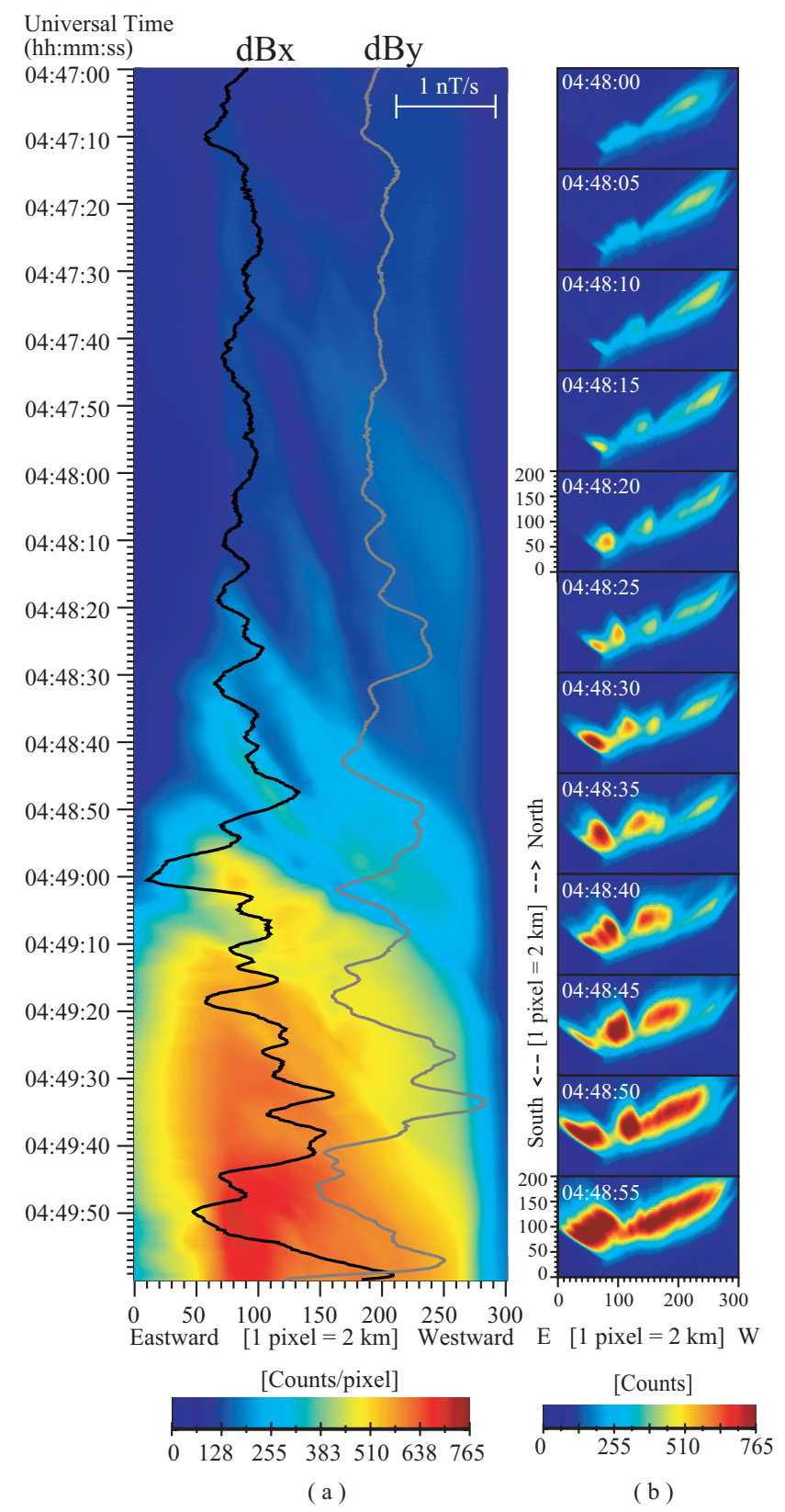

Fig. 6. (a) Temporal variation of brightening auroras in an east-west cross section from 04:47 UT to 04:50 UT on 8 January 2008 at Fort Smith. The vertical axis is time increasing downward. The horizontal axis is distance $[\mathrm{km}]$. The black and gray lines are $\mathrm{X}$ - and Y-components magnetic field fluctuations (40-s running average are subtracted) observed by a search coil magnetometer. (b) Brightening auroral images ( $0.1 \mathrm{~s}$ averages) every $5 \mathrm{~s}$ from 04:48:00 UT to 04:48:55 UT. The east-west keogram in (a) was obtained by integrating the images in (b) over the whole Y-axis distance.

mechanisms that launches small-scale upward field-aligned currents repeatedly with a period of $\sim 15 \mathrm{~s}$ and speeds of $\sim 8$ $16 \mathrm{~km} / \mathrm{s}$ at the auroral substorm onset.

\section{Summary}

We observed four events of brightening auroras at substorm onset using 30-Hz all-sky TV cameras during the THEMISground auroral campaign in January 2008. For two events, the brightenings occurred in the FoV of the all-sky cameras, and the other two events show characteristic expanding structure of brightening auroras propagating from outside the FoV. Dynamics and fine structures of these four brightening auroras are summarized as follows:

1. The brightening auroras appear simultaneously over $\sim 30-60-\mathrm{km}$ longitudinal segments within $1 \mathrm{~s}$.

2. One brightening aurora consists of small-scale ray structures with scale sizes of $\sim 10-100 \mathrm{~km}$, while the other brightening aurora is a single straight arc.

3. In the ionosphere, the longitudinal expansion speeds of brightening aurora are $\sim 20 \mathrm{~km} / \mathrm{s}$ in the first $10 \mathrm{~s}$, and in the following $10 \mathrm{~s}$ they decrease to $\sim 10 \mathrm{~km} / \mathrm{s}$.

4. For the brightening events started outside of FoV, the brightening auroras develop as periodic structures with longitudinal wavelength of $\sim 100 \mathrm{~km}$. The periodic signatures are also recognized in magnetic field fluctuations with a period of $\sim 15 \mathrm{~s}$ for event 4 .

5. Mapping these observations to $10 R_{E}$ on the equatorial plane of the magnetosphere, we found that the longitudinal scales $(30-60 \mathrm{~km})$ and the expansion speed $(20 \mathrm{~km} / \mathrm{s})$ of brightening auroras correspond to the ion gyro radii $(\sim 500-1400 \mathrm{~km})$ and Alfvén speed or fast ion flow speed $(\sim 400 \mathrm{~km} / \mathrm{s})$ in the plasma sheet.

Acknowledgements. We acknowledge M. Dollman for on-site assistance at Fort Smith. The observatories at Gillam and Fort Smith are Canadian Geospace Monitoring (CGSM) program core sites operated by the Canadian Space Agency. The campaign was carried out by the Solar-Terrestrial Environment Laboratory, Nagoya University in collaboration with the Canadian Space Agency, and with the support from the NORSTAR team of the University of Calgary. The magnetometers at Fort Smith and Gillam are part of the CARISMA array (www.carisma.ca), operated and deployed by the University of Alberta, funded by the Canadian Space Agency. This work was supported by a Grant-in-Aid for Scientific Research (19403010) of the Ministry of Education, Culture, Sports, Science, and Technology of Japan.

Topical Editor R. Nakamura thanks two anonymous referees for their help in evaluating this paper.

\section{References}

Akasofu, S. I.: The development of the auroral substorm, Planet Space Sci., 12, 273-282, 1964.

Angelopoulos, V., Kennel, C. F., Coroniti, F. V., Pellat, R., Kivelson, M. G., Walker, R. J., Russell, C. T., Baumjohann, W., Feldman, W. C., and Gosling, J. T.: Statistical Characteristics of 
Bursty Bulk Flow Events, J. Geophys. Res., 99(A11), 2125721280, 1994.

Angelopoulos, V., McFadden, J. P., Larson, D., Carlson, C. W., Mende, S. B., Frey, H., Phan, T., Sibeck, D. G., Glassmeier, K.-H., Auster, U., Donovan, E., Mann, I. R., Rae, I. J., Russell, C. T., Runov, A., Xhou, X., and Kepko, L.: Tail reconnection triggering substorm onset, Science, 321, 5891, doi:10.1126/science.1160495, 2008.

Baumjohann, W., Paschmann, G., and Cattell, C.: Average Plasma Properties in the Central Plasma Sheet, J. Geophys. Res., 94(A6), 6597-6606, 1989.

Cheng, C. and Lui, A.: Kinetic Ballooning Instability for Substorm Onset and Current Disruption Observed by AMPTE/CCE, Geophys. Res. Lett., 25(21), 4091-4094, 1998.

Cheng, C. Z.: Physics of substorm growth phase, onset, and dipolarization, Space Sci. Rev., 113, 207-270, 2004.

Donovan, E., Mende, S. B., Jackel, B., SyrjaÅNsuo, M., Meurant, M., Voronkov, I., Frey, H. U., Angelopoulos, V., and Connors, M.: The azimuthal evolution of the substorm expansive phase onset aurora, Proc. of International Conference on Substorms-8, edited by: SyrjaÅNsuo, M. and Donovan, E., Univ. of Calgary, Canada, pp. 55-60, 2006a.

Friedrich, E., Samson, J. C., and Voronkov, I.: Ground-based observations and plasma instabilities in auroral substorms, Phys. Plasmas, 8, 1104, doi:10.1063/1.1355678, 2001.

Donovan, E., Mende, S., Jackal, B., et al.: The THEMIS all-sky imaging array-system design and initial results from the prototype imager, J. Atmos. Sol. Terr. Phys., 68, 1472-1487, $2006 \mathrm{~b}$.

Liang, J., Donovan, E. F., Liu, W. W., Jackel, B., SyrjaÅNsuo, M., Mende, S. B., Frey, H. U., Angelopoulos, V., and Connors, M.: Intensification of preexisting auroral arc at substorm expansion phase onset: Wave-like disruption during the first tens of seconds, Geophys. Res. Lett., 35, L17S19, doi:10.1029/2008GL033666, 2008.

Lui, A. T. Y.: Current disruption in the Earth's magnetosphere: Observations and models, J. Geophys. Res., 101(A6), 1306713088, 1996.

Lui, A. T. Y.: Potential Plasma Instabilities for Substorm Expansion Onsets, Space. Sci. Rev., 113, 127-206, 2004.

Lyons, L. R., Voronkov, I. O., Donovan, E. F., and Zesta, E.: Relation of substorm breakup arc to other growth-phase auroral arcs, J. Geophys. Res., 107, 1390-1400, 2002.
Mann, I. R., Milling, D. K., Rae, I. J., Ozeke, L. G., Kale, A., Kale, Z. C., Murphy, K. R., Parent, A., Usanova, M., Pahud, D., Lee, E.-A., Amalraj, V., Wallis, D. D., Angelopoulos, V., Glassmeier, K.-H., Russell, C. T., Auster, H.-U., and Singer, H. J.: The upgraded CARISMA magnetometer array in the THEMIS era, Space Sci. Rev., 141, 413-451, 2008.

Mende, S. B., Harris, S. E., Frey, H. U., Angelopoulos, V., Russell, C. T., Donovan, E., Jackel, B., Greffen, M., and Peticolas, L. M.: The THEMIS array of ground based observatories for the study of auroral substorms, Space Sci. Rev., 141, 357-387, 2008.

Nakamura, R., Baker, D. N., Yamamoto, T., Belian, R. D., Bering III, E. A., Benbrook, J. R., and Theall, J. R.: Particle and Field Signatures During Pseudobreakup and Major Expansion Onset, J. Geophys. Res., 99(A1), 207-221, 1994.

Rae, I. J., Mann, I. R., Murphy, K. R., Milling, D. K., Parent, A., Angelopoulos, V., Frey, H. U., Kale, A., Watt, C. E. J., Mende, S. B., and Russell, C. T.: Timing and Localization of Ionospheric Signatures associated with Substorm Expansion Phase Onset, J. Geophys. Res., 114, A00C09, doi:10.1029/2008JA013559, 2009.

Shiokawa, K., Baumjohann, W., Haerendel, G., Paschmann, G., Fennell, J. F., Friis-Christensen, E., Luhr, H., Reeves, G. D., Russell, C. T., Sutcliffe, P. R., and Takahashi, K.: High-speed ion flow, substorm current wedge, and multiple Pi2 pulsations, J. Geophys. Res., 103, 4491-4507, 1998.

Shiokawa, K., Ieda, A., Nakajima, A., Sakaguchi, K., Nomura, R., Aslaksen, T., Greffen, M., Spanswick, E., Donovan, E., Mende, S. B., McFadden, J., Glassmeier, K.-H., Angelopoulos, V., and Miyashita, Y.: Initial results from the THEMIS-ground auroral campaign observations using $30-\mathrm{Hz}$ all-sky cameras in Canada: Longitudinal development of substorm brightening arcs, Ann. Geophys., in review, 2009.

Stasiewicz, K., Bellan, P., Chaston, C., Kletzing, C., Lysak, R., Maggs, J., Pokhotelov, O., Seyler, C., Shukla, P., Stenflo, L., Streltsov, A., and Wahlund, J.-E.: Small Scale Alfvénic Structure in the Aurora, Space Sci. Rev., 92, 423-533, 2000.

Tsyganenko, T. A.: A magnetospheric magnetic field model with a warped tail current sheet, Planet. Space Sci., 37(1), 5-20, 1989. 